\title{
Bruk av benzodiazepiner og cannabis blant unge voksne
}

\author{
Sammendrag \\ Bakgrunn. Leger forskriver benzodia- \\ zepiner hyppigere til pasienter med \\ høyt alkoholforbruk enn til andre. Vi vet \\ lite om benzodiazepinforskrivningen \\ til dem som bruker illegale rusmidler. \\ I denne tverrsnittsstudien undersøkte \\ vi forholdet mellom cannabisbruk og \\ benzodiazepinforskrivning hos unge \\ voksne.
}

\begin{abstract}
Materiale og metode. Data om bruk av cannabis og forskrivning av benzodiazepiner hos 2606 deltakere i spørreundersøkelsen Ung i Norge longitudinell (UiN) ble analysert. Vi koblet selvrapporteringsdata fra denne unders $\varnothing$ kelsen med data fra Nasjonalt reseptbasert legemiddelregister. Angst ble målt med seks ledd fra Symptom Checklist - 25. Andre forklaringsvariabler som ble unders $ø$ kt var alder, kjønn og bosted.
\end{abstract}

Resultater. 55 deltakere $(2,1 \%)$ hadde fått utlevert minst én resept på benzodiazepiner. Benzodiazepinforskrivning hadde signifikant sammenheng med hyppig cannabisbruk (justert OR 4,2) og høyt angstnivå (justert OR 8,5). Pasientens kjønn, alder eller om vedkommende var bosatt i Oslo eller omegn hadde ingen betydning for hvorvidt vedkommende fikk utskrevet benzodiazepiner.

Fortolkning. Cannabisbrukere får forskrevet mer benzodiazepiner enn andre. Det kan tenkes at de kan ha andre motiver enn symptomlindring, for eksempel rus, når de bruker disse midlene.

\author{
Hege Kornør \\ hege.kornor@kunnskapssenteret.no \\ Avdeling for legemiddelepidemiologi \\ Nasjonalt folkehelseinstitutt \\ Seksjon for legemidler og helseøkonomi \\ Nasjonalt kunnskapssenter for helsetjenesten \\ Postboks 7004 St. Olavs plass \\ 0130 Oslo

\section{Willy Pedersen} \\ Institutt for sosiologi og samfunnsgeografi \\ Universitetet i Oslo \\ og \\ Statens institutt for rusmiddelforskning (SIRUS)
}

\section{Tilmann von Soest}

Norsk institutt for forskning om oppvekst, velferd og aldring (NOVA)

\section{Ingeborg Rossow}

Statens institutt for rusmiddelforskning (SIRUS) og

Nasjonalt senter for selvmordsforskning

og -forebygging

Universitetet i Oslo

\section{Jørgen G. Bramness}

Avdeling for legemiddelepidemiologi

Nasjonalt folkehelseinstitutt

og

Senter for rus og avhengighetsforskning (SERAF) Universitetet i Oslo

Benzodiazepiner er mye brukt ved angstsymptomer og angstlidelser, som er blant de hyppigst forekommende psykiske lidelsene $(1,2)$. En behandlingsmessig utfordring ved bruk av benzodiazepiner er deres misbrukspotensial $(3,4)$. Samtidig vet vi at benzodiazepinbruk forekommer oftere blant dem som drikker alkohol svært ofte (5), men vi vet lite om forholdet mellom illegal rusmiddelbruk og benzodiazepinbruk.

Cannabis er det mest utbredte illegale rusmidlet i Norge. Det har vært vanlig å anta at ungdomsgruppene har det høyeste forbruket, men i de senere år er vi blitt klar over at det også er et betydelig forbruk blant unge voksne (6). Omkring 14\% i aldersklassen 20-30 år har brukt cannabis det siste året, og $40 \%$ en eller annen gang (7). En rekke studier har vist at angstsymptomer og angstlidelser forekommer oftere hos cannabisbrukere enn hos andre (8-12), men sammenhengen kan være kompleks. Inntak av cannabis kan ha ulike akutte effekter, avhengig av inntaksmåte, dose, personlighet, tidsramme, toleransegrad og en rekke andre miljø- og individfaktorer (6). Stoffet kan virke angstfremkallende hos noen og angstdempende hos andre (13). Etter lengre tids regelmessig bruk kan det å slutte med cannabis føre til abstinenssymptomer, som også kan innebære angst. Kronisk bruk kan også føre til angst, men samtidig viser en fersk unders $\varnothing$ kelse at sosial angst er en betydelig risikofaktor for cannabisavhengighet (14).

Bruk av benzodiazepiner forekommer oftere enn ellers hos personer med angstsymptomer og hos personer med generelt redusert psykisk helse $(5,15)$. Ettersom angstlidelser er mer utbredt blant cannabisbrukere (8-12), kunne man forvente at benzodiazepinbruk også var vanligere i denne gruppen. Dessuten kan en ruseffekt i tillegg til eller i stedet for en angstdempende virkning være en viktig motivasjon for benzodiazepinbruk blant cannabisbrukere. I de tilfellene der benzodiazepinbruken er motivert av en ruseffekt, er kanskje risikoen for utvikling av toleranse og avhengighet særlig stor. Etter omfattende litteratursøk i internasjonale databaser over vitenskapelige publikasjoner (Cochrane, Medline, PsychInfo, ISI Web of Science) har vi ikke kommet over studier der man har undersøkt lovlig bruk av benzodiazepinanxiolytika blant cannabisbrukere.

Formålet med denne studien var å undersøke i hvilken grad cannabisbrukere får forskrevet mer benzodiazepiner enn andre. Dersom det er tilfellet, kan det i så fall forklares ved at de i høyere grad enn andre rapporterer angstsymptomer?

\section{Materiale og metode}

Studien er basert på den omfattende Ung i Norge longitudinell-undersøkelsen (UiN), som er beskrevet tidligere (16). Studien startet i 1992, da et landsrepresentativt utvalg elever ved 67 norske ungdoms- og videregående skoler ble bedt om å delta. Elevene besvarte et spørreskjema i to undervisningstimer. Deltakelsesprosenten var 97. Elevene ble fulgt opp i 1994 med et nytt spørreskjema. De som ikke lenger gikk på samme skole, fikk spørreskjemaet i posten. Av dem som fortsatt gikk på skolen i 1994, var det

\section{Hovedbudskap}

- Forskrivning av benzodiazepiner til unge voksne i Norge er lite utbredt

- Unge voksne som bruker cannabis, får forskrevet benzodiazepiner oftere enn andre 
$92 \%$ som besvarte spørreskjemaet. Studien var opprinnelig planlagt til å omfatte bare to datainnsamlinger, og nytt samtykke måtte derfor innhentes for videre oppfølging. Bare personer som fortsatt gikk på samme skole som i 1992 ble spurt om videre deltakelse, og $91 \%$ av deltakerne samtykket da til dette. Disse respondentene mottok et spørreskjema i posten i 1999 ( $84 \%$ svar) og i 2005/06 ( $82 \%$ svar). Ved siste datainnsamling ble deltakerne bedt om å gi samtykke til kobling av spørreskjemadataene til data fra Nasjonalt reseptbasert legemiddelregister (Reseptregisteret) (17). I alt $90 \%$ av deltakerne samtykket, slik at data om reseptutlevering fra 2606 respondenter kunne bli trukket fra Reseptregisteret. Den kumulative svarprosenten var med dette 60 . For alle analyser som rapporteres her, brukte vi spørreskjemadata fra 2005/06 og reseptregisterdata. Nettoutvalget besto av 1459 kvinner $(56 \%)$ og 1147 menn (44\%). Gjennomsnittsalderen var 28 år (standardavvik 1,98), og 742 deltakere $(28 \%)$ var bosatt i Oslo eller omegn.

$\mathrm{Vi}$ innhentet data for alle respondenter fra Reseptregisteret. Registeret gir informasjon om dato for utlevering, ATC-koden (anatomical therapeutic classification) til det utleverte legemidlet og antall definerte døgndoser (DDD) forskrevet. Vi sammenliknet tall for den undersøkte gruppen med tall for hele aldersgruppen 26-30 år fra Reseptregisteret. Valgt periode var annet halvår 2005 og første halvår 2006.

Som mål på cannabisbruk benyttet vi selvrapporterte data fra Ung i Norge fra 2005/06 om hvor ofte deltakeren hadde brukt cannabis det siste året. Frekvensmålet hadde opprinnelig seks kategorier (fra 0 ganger til mer enn 50 ganger). For å få ned den statistiske usikkerheten på grunn av få eller ingen observasjoner i enkelte undergrupper ble bruken gruppert $i$ tre kategorier: 0 ganger, 1-10 ganger (sporadisk bruk) og $>10$ ganger (hyppig bruk).

Angstnivået til deltakerne målte vi ved hjelp av seks relevante testledd fra selvrapporteringsinstrumentet Symptom Checklist - 25 (SCL-25) $(18,19)$. De seks testleddene var spørsmål om i hvilken grad deltakeren de siste sju dagene hadde vært plaget av følgende: «plutselig redd uten grunn», «stadig redd eller engstelig», "matthet eller svimmelhet», «nervøsitet, indre uro», «lett for å gråte» og «lett for å klandre deg selv». Svarene ble skåret på en skala fra 1 («ikke plaget i det hele tatt») til 4 («veldig mye plaget»). Testleddene hadde tilfredsstillende indre konsistens (Cronbachs $\alpha=0,80$ ). Vi definerte angstnivået som høyt hvis gjennomsnittsskåren på de seks testleddene var 2,0 eller mer.

Benzodiazepinforskrivning ble definert som utlevering av minst én resept på ett eller flere av følgende benzodiazepiner i en 12månedersperiode (180 dager før til 180 dager etter spørreskjemabesvarelsen i 2005/ 06): diazepam (Stesolid, Vival, Valium), oksazepam (Alopam, Sobril), alprazolam (Xanor), klonazepam (Rivotril) og klobazam (Frisium). Vi undersøkte også hvor mange resepter som var levert inn i løpet av perioden og hvor mange definerte døgndoser reseptene gjaldt for.

Det er dokumentert at forekomsten av psykiske lidelser, cannabisbruk og benzodiazepinbruk har sammenheng med kjønn, alder og urbant versus ruralt bosted $(5,20)$ Vi brukte derfor kjønn, alder og grad av urbanitet (bosatt i Oslo eller omegn) som andre forklaringsvariabler i de multivariate analysene.

Det ble gitt informert skriftlig samtykke fra deltakerne til å koble deres svar til sentrale helseregistre. Koblingen ble godkjent av regional etisk komité Sør, konsesjon for opprettelse av en koblet datafil er gitt fra Datatilsynet. Analyser ble gjort ved hjelp av SPSS 15.0 for Windows.

De avhengige variablene var benzodiazepinforskriving for hele utvalget og antall definerte døgndoser og innleverte resepter for benzodiazepinbrukerne. $\mathrm{Vi}$ beregnet oddsratio (OR) med $95 \%$ konfidensintervall ( $95 \% \mathrm{KI}$ ) for kategoriske variabler og sammenliknet medianer for de kontinuerlige variablene ved hjelp av Mann-Whitneys U-test. Til multivariate analyser brukte vi logistisk regresjon, hvor vi justerte for forklaringsvariabler som predikerte utfallsmålet med $p<0,20$, som er anbefalt som signifikansnivå for forklaringsvariabler (21). Vi undersøkte også interaksjonseffekten av angstnivå og cannabisbruk på benzodiazepinforskrivning ved å sammenlikne log likelihood for modellen med hovedeffektene og en modell med både hovedeffekter og interaksjonseffekt.

\section{Resultater}

55 deltakere $(2,1 \%)$ fikk utlevert minst én resept på benzodiazepiner i perioden 180 dager før til 180 dager etter at de svarte på spørreskjemaet (tab 1). I alt hadde 379 deltakere $(14,5 \%)$ brukt cannabis det siste året, og litt over halvparten av disse (194 deltakere) hadde brukt cannabis mer enn ti ganger siste år. Av de 2592 deltakerne som hadde besvart spørsmålene om angstsymptomer, hadde $244(9,4 \%)$ et høyt angstsymptomnivå. Av cannabisbrukerne hadde $53(14,8 \%)$ et høyt symptomnivå, det samme var tilfellet for $191(8,8 \%)$ av dem som ikke hadde brukt cannabis siste år $(\mathrm{OR}=1,8$; $95 \%$ KI $1,3-2,4)$. Ti deltakere $(0,4 \%)$ med et høyt angstnivå hadde både brukt cannabis og fått forskrevet benzodiazepiner.

Bivariate analyser viste at både hyppig cannabisbruk og høyt angstnivå var signifikante prediktorer for forskrivning av benzodiazepiner (tab 1). Verken kjønn, alder eller urbanitet hadde signifikant sammenheng med forskrivning av benzodiazepiner. Både hyppig cannabisbruk og høyt angstnivå forble prediktorer for forskrivning av benzodiazepiner ved justering for hverandre og for kjønn i de multivariate analysene. Vi fant ingen interaksjonseffekt mellom cannabisbruk og angstnivå.

Cannabisbrukerne var mottakere i to tredeler av tilfellene av benzodiazepinforskrivning i utvalget (tab 2). Sammenlikningen av medianer viste ingen forskjell i totalt antall definerte døgndoser mellom cannabisbru-

Tabell 1 Sammenhengen mellom det å få forskrevet benzodiazepiner og cannabisbruk, angstnivå, kjønn, alder og urbanitet. Bivariate sammenhenger er vist som antall i de første kolonnene og som oddsratio (OR) med $95 \%$ konfidensintervall (KI). De to siste kolonnene viser OR med $95 \%$ $\mathrm{KI}$ i de multivariate analysene hvor justeringer er foretatt

\begin{tabular}{|c|c|c|c|c|c|c|}
\hline & $\begin{array}{l}\text { Ikke for- } \\
\text { skrevet }\end{array}$ & Forskrevet & & & & \\
\hline Cannabisbruk siste år & Antall & Antall & OR & $95 \% \mathrm{KI}$ & Justert OR ${ }^{1}$ & $95 \% \mathrm{KI}$ \\
\hline Ikke brukt & 2192 & 35 & (ref) & & (ref) & \\
\hline Brukt $\leq 10$ ganger & 178 & 7 & 2,5 & $1,1-5,6$ & 2,3 & $1,0-5,4$ \\
\hline Brukt > 10 ganger & 181 & 13 & 4,5 & $2,3-8,7$ & 4,2 & $2,0-8,6$ \\
\hline \multicolumn{7}{|l|}{ Angstnivå } \\
\hline Lavt $(<2,00)$ & 2320 & 28 & (ref) & & (ref) & \\
\hline Høyt $(\geq 2,00)$ & 218 & 26 & 9,9 & $5,7-17,2$ & 8,5 & $4,9-14,9$ \\
\hline \multicolumn{7}{|l|}{ Kjønn } \\
\hline Mann & 1129 & 18 & (ref) & & (ref) & \\
\hline Kvinne & 1422 & 37 & 1,6 & $0,9-2,9$ & 1,7 & $0,9-3,2$ \\
\hline \multicolumn{7}{|l|}{ Alder (år) } \\
\hline$\leq 28$ & 1270 & 28 & (ref) & & (ref) & \\
\hline$>28$ & 1276 & 27 & 1,0 & $0,6-1,6$ & 1,1 & $0,6-1,9$ \\
\hline \multicolumn{7}{|c|}{ Urbanitet (bosatt i Oslo/omegn) } \\
\hline Nei & 1772 & 38 & (ref) & & (ref) & \\
\hline $\mathrm{Ja}$ & 725 & 17 & 1,1 & $0,6-2,0$ & 1,0 & $0,5-1,8$ \\
\hline
\end{tabular}

1 Justert for cannabisbruk, angstnivå og kjønn 
Tabell 2 Antall definerte døgndoser (DDD) og resepter hos deltakere som fikk forskrevet benzodiazepiner etter cannabisbruk siste år

DDD

\section{Cannabisbruk}

siste år

Ikke brukt

Brukt

Totalt

\begin{tabular}{cc} 
Antall & Sum \\
\hline 35 & 1115 \\
20 & 2228 \\
55 & 3343
\end{tabular}

$\begin{array}{cc}\text { Median } & \text { Gjennomsnitt } \\ 12,5 & 31,9 \\ 10,0 & 111,4 \\ 12,0 & 60,8\end{array}$

Spredning
$\begin{gathered}4-400 \\ 4-500 \\ 4-500\end{gathered}$

P-verdi

0,487

P-verdi
0,487

Sum
66
118
184

Median
1,0
1,5
1,0

Resepter

kere og dem som ikke hadde brukt cannabis. Cannabisbrukerne hadde imidlertid fått flere resepter enn ikke-brukerne.

Dataene fra Reseptregisteret for hele aldersgruppen 26-30 år viste at 8690 personer hadde levert inn til sammen 44116 resepter på 1049538 definerte døgndoser ved et norsk apotek i løpet av annet halvår 2005 og første halvår 2006. Det gir en prevalens på 3,0\%. Gjennomsnittlig totalt antall definerte døgndoser per benzodiazepinbruker $\mathrm{i}$ totalpopulasjonen var 121, og de hadde levert inn i gjennomsnitt 5,1 resepter hver. Tilsvarende gjennomsnitt i studieutvalget var henholdsvis 61 og 3,4 .

\section{Diskusjon}

Denne studien har vist at benzodiazepiner forskrives sjelden til unge voksne i Norge. Vi så at cannabisbruk generelt og spesielt hyppig cannabisbruk og høyt angstnivå uavhengig av hverandre var tett knyttet til benzodiazepinforskrivning, mens kjønn, alder og urbanitet ikke hadde noen betydning for forskrivningen av benzodiazepiner til den studerte gruppen. Blant benzodiazepinbrukerne fikk de som brukte cannabis i løpet av ett år flere resepter enn andre, og den relativt lille gruppen cannabisbrukere sto for to tredeler av den totale benzodiazepinbruken i dette utvalget av unge voksne. Forekomsten av benzodiazepinforskrivning til den generelle befolkningen av unge voksne i Norge var noe høyere enn forskrivningen til dette utvalget, og den generelle befolkningen hadde et større forbruk per bruker.

Vi kjenner ikke til andre studier av lovlig bruk av benzodiazepiner og cannabisbruk. Våre resultater kan derfor ikke tolkes i lys av tidligere forskning, og vår studie er trolig unik i sitt slag. Den forhøyede forekomsten av benzodiazepinforskrivning til cannabisbrukerne var som forventet - ut fra eksisterende kunnskap om overhyppighet av angstsymptomer og angstlidelser hos dem som bruker cannabis (8-12). Denne overhyppigheten av angstsymptomer ble bekreftet i vår undersøkelse.

Den sterke sammenhengen mellom høyt angstnivå og benzodiazepinforskrivning var lite overraskende, men høy angstskår var ikke noen forutsetning for forskrivning av benzodiazepiner. Kun halvparten av benzodiazepinbrukerne hadde høy angstskår. Dette kan skyldes at reseptene gjaldt andre indikasjoner enn angst (f.eks. søvnvansker), at ben- zodiazepinbruken var rusmotivert eller at medikamentene hadde hatt en angstdempende effekt. Men det kan også bety at testleddene vi har brukt her, ikke fanger opp angst godt nok, at terskelverdien $(2,0)$ var satt for høyt eller at tidsrommene for legemiddelbruk og symptomrapportering ikke er overlappende. Det siste forsøkte vi å unngå ved å avgrense observasjonstiden for benzodiazepinbruk. Et tidsvindu på 180 dager i hver retning i forhold til symptomrapporteringen kan ha vært for mye, men vi valgte ikke å gjøre observasjonstiden kortere fordi det ville redusert antallet benzodiazepinbrukere $\mathrm{i}$ utvalget så mye at resultatene ville gi lite mening. Å sette ned terskelverdien for høyt angstnivå forandret ikke resultatene.

Forskjellen i benzodiazepinforskrivning mellom dette utvalget og den generelle befolkningen av unge voksne skyldes trolig en seleksjonsskjevhet hvor deltakere med den tyngste problembelastningen har falt fra Ung i Norge-undersøkelsen underveis. På samme måte kan cannabisbrukere utgjøre en betydelig andel av de frafalne deltakerne. Det er derfor grunn til å tro at den reelle forekomsten av cannabisbruk er noe høyere blant unge voksne i populasjonen enn forekomsten i denne studien.

Denne studien har flere sterke sider. Vi har data fra et landsomfattende tilfeldig utvalg. Det er vanskelig å få gode selvrapporteringsdata om bruk av medikamenter, derfor var det en fordel at vi kunne koble Ung i Norge-data med reseptregisterdata. Men vi kan også peke på svakheter: Selv om studien har god responsrate, har vi antakelig et frafall fra de mest belastede gruppene i befolkningen. Det var høyere forskrivning av benzodiazepiner i frafallet, og det er også grunn til å anta at det er høyere bruk av cannabis. Vi har dessuten basert oss på tverrsnittsdata. En longitudinell design ville være et bedre bidrag til forståelsen av kausale forhold. Vi har heller ikke noe mål på benzodiazepinbruk. Reseptregisteret inneholder ikke informasjon om hvorvidt personen faktisk har tatt legemidlet som forskrevet, heller ikke noe om indikasjon for behandlingen. Dessuten mangler vi data om ikke-forskrevet bruk av benzodiazepiner. Mange cannabisbrukere har kontakt med et illegalt marked for psykoaktive stoffer, hvor også benzodiazepiner tilbys (22).

Angstdempende benzodiazepiner er lite brukt av unge voksne. Forskrivning bør kun skje etter nøye overveielse fra legen og bare som en nødløsning - selv når pasientene presenterer angstsymptomer. At cannabisbrukere synes å stå for størstedelen av benzodiazepinbruken i denne aldersgruppen, gjør at legen bør tenke seg ekstra godt om og passe på at ikke han eller hun bidrar til uheldige mestringsstrategier overfor angst og eventuelt også til pasientens misbruksproblemer. Vår undersøkelse kan ikke si oss noe om hvem som tar initiativet til forskrivning av disse medikamentene, men berettiger at legen kan problematisere rus av legale og illegale medikamenter når pasienter presenterer angstsymptomer eller behov for benzodiazepiner ved sitt legebesøk.

\section{Oppgitte interessekonflikter: Ingen}

\section{Litteratur}

1. Kringlen E, Torgersen S, Cramer V. A Norwegian psychiatric epidemiological study. Am J Psychiatry 2001; 158: 1091

2. Kessler RC, McGonagle KA, Zhao S et al. Lifetime and 12-month prevalence of DSM-III-R psychiatric disorders in the United States. Results from the National Comorbidity Survey. Arch Gen Psychiatry 1994; $51: 8-19$

3. de Wit H, Griffiths RR. Testing the abuse liability of anxiolytic and hypnotic drugs in humans. Drug Alcohol Depend 1991; 28: 83-111.

4. Uhlenhuth EH, Balter MB, Ban TA et al. International study of expert judgment on therapeutic use of benzodiazepines and other psychotherapeutic medications: IV. Therapeutic dose dependence and abuse liability of benzodiazepines in the long-term treatment of anxiety disorders. J Clin Psychopharmacol 1999; 19: 23-9S.

5. Hausken AM, Skurtveit S, Rosvold EO et al. Psychotropic drug use among persons with mental distress symptoms: a population-based study in Norway. Scand J Public Health 2007; 35: 356-64.

6. Hall W, Pacula RL. Cannabis use and dependence. Public health and public policy. Cambridge: Cambridge University Press, 2003.

7. Pedersen W. Hasjbruk hos unge voksne. Tidsskr Nor Legeforen 2008; 128: 1825-8.

8. Bonn-Miller MO, Zvolensky MJ, Leen-Feldner EW. Marijuana use among daily tobacco smokers: relationship to anxiety-related factors. Journal of Psychopathology and Behavioral Assessment 2005; 27: 279-89.

9. Degenhardt L, Hall W, Lynskey M. The relationship between cannabis use, depression and anxiety among Australian adults: findings from the National Survey of Mental Health and Well-Being. Soc Psychiatry Psychiatr Epidemiol 2001; 36: 219-27.

10. van Laar M, van Dorsselaer S, Monshouwer K, de Graaf R. Does cannabis use predict the first incidence of mood and anxiety disorders in the adult population? Addiction 2007; 102: 1181-2.

11. Zvolensky MJ, Lewinsohn P, Bernstein A et al. Prospective associations between cannabis use, abuse, and dependence and panic attacks and disorder. J Psychiatr Res 2008; 42: 1017-23. 
12. Zvolensky MJ, Bernstein A, Sachs-Ericsson N et al. Lifetime associations between cannabis, use, abuse, and dependence and panic attacks in a representative sample. J Psychiatr Res 2006; 40: 477-86.

13. Leweke FM, Koethe D. Cannabis and psychiatric disorders: it is not only addiction. Addict Biol 2008; 13: $264-75$.

14. Buckner JD, Schmidt NB, Lang AR et al. Specificity of social anxiety disorder as a risk factor for alcohol and cannabis dependence. J Psychiatr Res 2008; 42: 230-9.

15. Shader RI, Greenblatt DJ. Drug-therapy - use of benzodiazepines in anxiety disorders. $N$ Engl J Med 1993; 328: 1398-405.

16. Wichstrøm L. Ung i Norge. Norsk Epidemiologi 2000; 12: $231-7$

17. Furu K. Establishment of the nationwide Norwegian Prescription Database (NorPD) - new opportunities for research in pharmacoepidemiology in Norway. Norw J Epidemiol 2008; 18: 129-36.

18. Hammer T, Vaglum P. Initiation, continuation or discontinuation of cannabis use in the general population. Br J Addict 1990; 85: 899-909.

19. Strand BH, Dalgard OS, Tambs K et al. Measuring the mental health status of the Norwegian population: a comparison of the instruments SCL-25,

SCL-10, SCL-5 and MHI-5 (SF-36). Nord J Psychiatry 2003; $57: 113-8$.

20. Kringlen E, Torgersen S, Cramer V. Mental illness in a rural area - a Norwegian psychiatric epidemiological study. Soc Psychiatry Psychiatr Epidemiol 2006; 41: 713-9.

21. Greenland S, Rothman KJ. Introduction to stratified analysis. I: Rothman KJ, Greenland S, red. Modern epidemiology. Los Angeles, CA: Lippincott-Raven, 1998: 253-79.

22. Sandberg S, Pedersen W. «Rett fra pikerommet, med ransel på ryggen?»: om ungdom som oppholdt seg rundt Plata. NOVA-rapport nr. 6/2005. Oslo: Norsk institutt for forskning om oppvekst, velferd og aldring, 2005.

Manuskriptet ble mottatt 4.2. 2009 og godkjent 4.3. 2010. Medisinsk redaktør Are Brean. 